Title: Information management and governance in UK higher education institutions: bringing IT in from the cold.

\author{
Authors: Michael Coen and Ursula Kelly
}

'In the $21^{\text {st }}$ Century, IT Governance is, within the broader corporate governance context, critical for all organisations. Those without an IT governance strategy face significant risks; those with one perform measurably better.' (Calder 2005)

'There has been little field based research on IT governance, and few publications help managers understand the issues involved in designing effective governance structures and processes...' (Weill and Ross 2004)

\title{
Introduction
}

Investment in information systems and information technology (IT) now constitutes a significant proportion of expenditure within higher education institutions (HEIs). (HEFCE 1998 and UCISA 2005a.) IT has become increasingly embedded within, and integral to, support for core institutional activity including teaching and research as well as supporting student learning and administration. Growing emphasis on good governance practice in HEls (CUC 2004) has converged with raised awareness of the scale of institutional expenditure on IT and its expanding business-critical nature.

The concept of IT governance has emerged as a response to the growing pressure on all organisations to ensure that they are achieving value for money from their investment in IT and information systems, which includes ensuring that investment is aligned with organisational strategic priorities. It is based on the premise that how IT is used and managed within an organisation really matters and that an institutional approach to IT needs to become embedded into central strategic planning.

This article seeks to highlight some of the key issues for HEls in relation to IT governance and summarises a new framework approach to IT governance in higher education, which has been developed for the Joint Information Systems Committee (JISC). Throughout this article the term 'IT' in its broadest sense, to denote not only physical hardware and software and infrastructural systems but also to encompass the holistic issues associated with how an institution uses technology to support its business.

\section{What is IT governance?}

IT governance is essentially about ensuring the establishment of sound organisational structures and processes to support informed decision-making about IT investment and the role of IT within an organisation, embedding a comprehensive approach to risk management and performance measurement of IT at an institutional strategic level. The IT Governance Institute defines IT governance as

'an integral part of enterprise governance and consists of the leadership and organizational structures and processes that ensure that the organization's IT sustains and extends the organization's strategies and objectives'.

To that extent, IT governance can be seen as forming a key part of the overall governance structure within an organisation, rather than being something entirely separate. However, as a key element of organisational resources, on which the delivery of many of an organisation's objectives may depend, it needs to be actively considered within the governance process and institutional planning.

\section{Challenges for HEls}


The management and governance of IT within HEls can appear somewhat intractable information systems and IT now underpin almost every activity within $\mathrm{HE}$ and therefore a large variety of systems have to be considered; systems cross internal organisational boundaries and consequently management structures can be complex; the use of information technology is often embedded within other processes making it difficult to isolate and review its effectiveness. This complexity makes it increasingly difficult for senior management to develop an informed view of the investment business cases presented to them and to be sure that all institutional IT expenditure is to good purpose. Some of the specific issues facing HEIs include:

- the speed of change driven or facilitated by IT. New technologies (eg mobile devices, wireless computing, virtual learning environments and portal software, digital libraries, etc.) offer new possibilities for teaching, learning and research support - as well as having extensive impact on administration and 'back-office' processes. The long-term adoption of these technologies requires the development of more sophisticated models to justify additional investment and more robust plans for sustainability.

- the growing raft of legislation governing the storage and use of information (eg the Data Protection Act, Regulation of Investigatory Powers Act, Freedom of Information Act, Disability Discrimination Act, copyright law, etc.) Consequently the institution has an increased responsibility to ensure that it has sufficiently robust policies in place for compliance.

- the increasing level of IT awareness and knowledge among users and key client groups, particularly the student body, leading to demand for better and more extensive electronic services.

- the increased business risk to the institution should those systems fail, as IT and information systems become more deeply embedded in all the activities of HEls

- the inexorable drive towards more centralisation of IT-related service provision (eg network provision, access management, virtual learning environments- data storage and back-up, etc.) even in institutions that have traditionally operated highly devolved budgetary management and control structures. The sheer scale of institutional requirements and increasing need for compatibility of internal systems means that institution-wide solutions need to be found.

\section{Towards an IT governance framework for higher education institutions}

Over the past decade UK HEls began to focus on the cost involved in their use of information systems and technology, although its increasingly embedded nature means that few institutions (if any) have been able to accurately identify all of the costs (HEFCE,1998). More recently, the widespread adoption of good practice guidelines on stewardship of assets and risk management (HEFCE, 2003. CUC, 2004), have focussed institutional attention on the levels of risk associated with their IT operations.

Latterly it is becoming recognised that HE IT investment and institutional information systems cannot be viewed on a 'stand-alone' basis. Rather the institution's approach to, and use of, IT needs to be included as a core element in institutional strategic planning. It may be noted that IT Directors in UK HE have recently identified the need for a 'strategic approach to infrastructure' and the incorporation of 'IT in institutional planning' as being among the most important issues facing the sector (UCISA, 2005b.)

All of these issues led the JISC to commission the development of an IT governance framework that could assist HEls. The authors were asked to develop a framework and selfassessment toolkit to assist institutions in considering, and to some extent untangling, the complex array of issues associated with the management and governance of their information systems.

JISC had recognised that guidelines for IT governance would need to meet the specific needs of higher education institutions. HEls have a complex set of cultural and motivational drivers, arising from their status as not-for-profit organisations, which directly impacts on their management and governance. Many of the principles underlying the development of IT governance frameworks in the commercial sector may be equally valid for higher education institutions (for example ensuring clear decision-making structures and approaches to risk 
assessment). However others (such as specific types of performance measurement, particularly profit-related financial performance measures) are not as directly applicable. Weill \& Ross (2004) highlighted some of the issues for non-profit-making organisations:

\begin{abstract}
'... A frustration facing not-for-profit executives is that many of the management frameworks and measures are designed for profit-seeking organisations where the performance measures of profit, shareholder value and corporate citizenship are clear. ... leaders of not-for profit organisations need a different management framework to help strategise and govern...'
\end{abstract}

\title{
A summary of the developing framework
}

In order to help resolve some of this complexity and to allow institutions to take a structured approach to assessing their information systems, the project team developed the framework shown in figure 1. This framework was designed to be sufficiently flexible to be of use to different HEls - large or small, ancient or modern and to take into account the different cultural and financial imperatives governing HEIs. The framework is built around five perspectives - governance, management, resources, structures and services. The position of services at the centre of the diagram indicates the service-centred ethos underlying the framework. These services, delivered through the institution's information systems, use resources and are organised through the organisational structures and processes that are put in place.

As reflected in the framework, the services, resources and structures are the primary components of information systems management. The governance activity sits above and overlaps with management, and is primarily concerned with ensuring that management is effective and that activities are aligned to institutional priorities.

The 'Governance' perspective is primarily concerned with three key issues:

- Vision - determining the institution's strategic goals and direction.

- Alignment - seeking alignment of information systems strategy and investment with the institutional vision and strategy.

- Assurance- being able to provide assurance to all institutional stakeholders that institutional information systems are aligned to strategy.

The 'Management' perspective is subdivided into the three main areas of management responsibility: resources (or the 'inputs' to the process), organisation (or the 'process' itself) and services (or the 'outputs' of the process). Each is described in detail below.

The 'Resources' perspective is concerned with the resources that are required in order to deliver the institution's information systems:

- People -ensuring that the expertise and skills of staff and students are sufficient to effectively use and/or support the information systems and technologies at their disposal.

- Technology - ensuring that decisions about investment in technology are wellinformed and that the technologies an institution acquires are secure, robust and capable of being used effectively.

- Finance - ensuring that effective mechanisms are in place to secure, allocate, sustain and manage investments in new and existing systems.

The 'Organisation' perspective is concerned with the organisation and procedural structures that are put in place to control the institution's investment in information systems and IT. Here, the key issues are:

- Structures - ensuring that the organisation's structures effectively support the information systems and services.

- Policies - ensuring that documented policies and procedures are in place to make each stakeholder aware of their responsibilities and rights in relation to the use of information, information systems and IT. 
- Decision-Making - ensuring that suitable individuals or groups are empowered to make decisions and that they are presented with sufficient information and supporting tools to enable them to act effectively.

The 'Service' perspective covers all those activities that are 'outputs' of the institution's investment in information systems and IT. These activities can be categorised in three ways:

- Systems - ensuring that institutional systems (both IT-based and manual) offer coordinated, supported services to users.

- Projects - ensuring that procedures are in place to guide ,monitor and evaluate information systems 'project' work whether the projects are exploratory pilots or fullscale implementations.

- Service Delivery - ensuring the effective and efficient management of service delivery.

The toolkit which accompanies the framework contains a set of self-assessment questions and good practice guides to assist institutions in assessing the robustness of their approach to the management and governance of information systems and IT. The aim of the toolkit is to facilitate a cycle of evaluation and improvement to ensure that activity and investment remains aligned with institutional strategies and priorities. This process is currently being piloted in a number of HE institutions throughout the UK, with the resultant feedback informing further refinement of the toolkit and framework. More information can be found at http://www.insight.strath.ac.uk/projects/itgov/index.htm

\section{Conclusions}

The widespread and rapid evolution of IT usage in higher education has driven the need for institutions to effectively evaluate and assess the management of IT systems at a strategic level. There is considerable evidence of good practice in IT operational management in HEls throughout the UK, including significant usage of IT industry standards and management tools (Breslin et al 2005) such as the Information Technology Infrastructure Library (ITIL $®$ ). However it is increasingly recognised, not least by HE IT Directors, that it is time for IT to be integrated and embedded into overall institutional strategic perspectives. Only in this way can an institution be sure that it is effectively exploiting one of its most expensive resources and that IT becomes a valuable asset rather than a costly liability. The framework for IT governance proposed in this paper is intended to provide a starting point to assist institutions in the process of identifying and defining the role of IT within their own organisation's planning and governance.

'IT Governance is not a state; it is a process, an ongoing undertaking that will constantly be redefined. IT Governance is inherently tied into corporate or enterprise governance, and will both reflect and help shape the changes that organisations undergo over a period of time. ...' (The Butler Group, 2003)

\section{References:}

Butler Group (2003), IT Governance - The Exploitation, Control and Measurement of Information and Technology Resources. (London, Butler Direct Limited)

Breslin, C., Coen, M. and Kelly, U (2005) - Information Systems Management and Governance - Survey Results Analysis . URL: http://www.insight.strath.ac.uk/projects/itgov/docs/survey results.pdf

Calder, A. (2005) IT Governance - Guidelines for Directors (London, IT Governance Publishing) pp 11

CUC - The Committee of University Chairman (2004) Guide for members of higher education governing bodies. URL: http://www.hefce.ac.uk/pubs/hefce/2004/04 40/

HEFCE (1998) Information Systems and Technology Management Value for Money Study URL: http://www.hefce.ac.uk/pubs/hefce/1998/98 42.htm 
HEFCE (2003) Model Financial Memorandum. URL:

http://www.hefce.ac.uk/pubs/hefce/2003/03 54/

The IT Governance Institute.: http://www.itgi.org/

UCISA - The Universities and Colleges Information Systems Association (2005a) Higher Education Information Technology Statistics Survey

http://www.ucisa.ac.uk/activities/stats/index html

UCISA - The Universities and Colleges Information Systems Association (2005b) Top

Concerns

http://www.ucisa.ac.uk/activities/surveys/tc/2005

Weill, P. and Ross, J. (2004) IT Governance (Boston, Harvard Business School Press) pp 190 